\title{
Purple sweet potato anthocyanin exerts antitumor effect in bladder cancer
}

\author{
WEI-LIN LI, HONG-YUAN YU, XIAN-JUN ZHANG, MANG KE and TAO HONG \\ Department of Urology, Taizhou Hospital Affiliated to Wenzhou Medical University, \\ Taizhou, Zhejiang 317000, P.R. China
}

Received November 15, 2017; Accepted April 17, 2018

DOI: $10.3892 /$ or.2018.6421

\begin{abstract}
Bladder cancer (BC) is the most common malignant disease. The developing of economically sustainable and available agents for the treatment of $\mathrm{BC}$ is required. Purple sweet potato anthocyanin (PSPA) has been shown to have antitumor abilities. The present study aimed to evaluate the potential role of PSPA in BC treatment. CCK-8 assay was used to assess the viability of $\mathrm{BC}$ cells. Flow cytometry assays were performed to evaluate the mitochondrial membrane potential (MMP), cell apoptosis and cell-cycle distribution. Real-time PCR (RT-PCR) and western blot analysis were performed to determine the expression of the target genes. The results of this study revealed that PSPA reduced the viability of BC in a dose-dependent manner. The MMP collapse was aggravated by the PSPA treatment. The apoptosis rate was higher in the PSPA groups than that in the control group. The expression of the pro-apoptosis genes, including cleaved caspase-3, Fas, Fasl, Bcl-2-associated X proteins (Bax) and anti-apoptotic gene (Bcl-2) was induced and decreased by PSPA, respectively. The cell-cycle progression was suppressed by the presence of PSPA. The activation of the phosphatidylinositol4,5-bisphosphate 3-kinase/Akt (PI3K/Akt) signaling pathway was suppressed by PSPA treatment during BC treatment. The PI3K/Akt signaling was closely related to the antitumor effect of PSPA in BC. The present study provided evidence regarding the treatment of $\mathrm{BC}$ and enhanced the understanding of the potential role that PSPA plays in cancer prevention.
\end{abstract}

\section{Introduction}

Bladder cancer (BC) is the most common malignant disease in elderly patients throughout the world. BC typically arises

Correspondence to: Dr Hong-Yuan Yu, Department of Urology, Taizhou Hospital Affiliated to Wenzhou Medical University, 150 Ximen Road, Linhai, Taizhou, Zhejiang 317000, P.R. China

E-mail: yuhy@enzemed.com

Key words: anthocyanin, purple sweet potato anthocyanin, antitumor, bladder cancer from urinary bladder tissue, where it predominates across North America and Western Europe. The incidence of BC is more common in males than in females $(1,2)$. The primary risk factors for BC consist of aging, smoking, chronic irritation, family genetic history and chemical exposure $(3,4)$. There are sophisticated techniques for the treatment of BC, however previous literature has stated that the treatment of $\mathrm{BC}$ remains a challenge $(5,6)$. Developing economically sustainable and available agents for the treatment of $\mathrm{BC}$ is urgently needed within the scientific community.

Anthocyanidins are antioxidant polyphenolic compounds that are found in fruits and vegetables, where they are refined into anthocyanins (7). Purple sweet potato (PSP) obtains its unique color due to the presence of anthocyanins, and therefore it is recognized as a healthy food and used as a food colorant. Recent studies have revealed that the purple sweet potato anthocyanin (PSPA) has various health benefits such as antioxidant, antihypertensive, as well as liver and retina protective (8-10). Studies in humans and rats revealed that PSPA is absorbed into the body, where it is rapidly detected in the blood $(11,12)$. The antitumor effect of the PSPA has gained attention, since it has been demonstrated to have an effect in rectal (13), colon (14) and stomach cancer (15). However, the potential function that PSPA plays in BC remains undetermined.

Molecular-targeted therapy is a hot topic in cancer prevention, including $\mathrm{BC}$, where it is thought to disrupt the molecular events associated with tumor proliferation (6). The phosphatidylinositol 3-kinase (PI3K) pathway is an important signaling pathway within living cells. This pathway is responsible for regulating cell survival and cell proliferation (16). The abnormal activation of the PI3K pathway has been identified in multiple cancers $(17,18)$. The components involved in this pathway, including Akt, could serve as possible therapeutic targets during cancer development $(19,20)$. The PI3K/Akt is a promising molecular target among the treatments of BC.

It appears plausible that PSPA could be involved in the physiological development of BC. The present study aimed to investigate whether PSPA exerted antitumor effects on BC by detecting its effect on cell apoptosis and cell cycle arrest of $\mathrm{BC}$ cells in vitro. The underlying molecular mechanisms were also explored. This study aimed to contribute to the treatment of BC and enhance the understanding of the possible role that PSPA plays in cancer prevention. 


\section{Materials and methods}

PSPA preparation. The PSP cultivars $\mathrm{Zi} \mathrm{A} 1$, Anhui $\mathrm{Zi}$, Chuanshan $\mathrm{Zi}$, Jishu 18 and $\mathrm{Zi}$ A0 were obtained from the Academy of Agricultural Sciences in Xuzhou (Jiangsu, China). Based on previously described methods (21), 5 to $8 \mathrm{~mm}$ PSP slices were dried under the condition of $50^{\circ} \mathrm{C}$ (moisture content in dry products $<12 \%$ ). Subsequently, the dry PSP powder was mixed with acidizing solution (95\% ethanol:1 M HCL=9:1, $\mathrm{v} / \mathrm{v}$ ). After $3 \mathrm{~h}$, the mixture was centrifuged for $20 \mathrm{~min}$ at $8000 \mathrm{x} \mathrm{g} / \mathrm{min}$. The supernatant was decreased using petroleum ether (extract:petroleum ether $=1: 2$ ). The concentrate was absorbed by a macroporous resin (AB-8) and eluted by an ethanol solution (containing $0.01 \% \mathrm{HCL}$ ) at a flow rate of $1 \mathrm{ml} / \mathrm{min}$. The anthocyanin effluent was harvested and concentrated. The solutions were diluted to perform the spectral scanning using the UV-vis spectrophotometer model Genesys 10S (Thermo Fisher Scientific, Inc., Waltham, MA, USA). The absorbance was assessed at the maximum absorption peak. The total content of PSPA was calculated according to the following formula: $\mathrm{FW}_{\mathrm{W}}=(\mathrm{ExV}) /(98.2 \times \mathrm{M}) \times 100$ [E, optical density; V, final volume (ml), M, sample weight (g), 98.2, the molar extinction coefficient of anthocyanins].

Cell culture. Bladder cell lines, 5637 and T24, were purchased from the American Type Culture Collection (ATCC, Manassas, VA, USA). The cells were cultured in RPM-1640 and McCoy's 5a (ATCC) medium with $10 \% \mathrm{FBS}$, at $37^{\circ} \mathrm{C}$ in an incubator containing $5 \% \mathrm{CO}_{2}$ atmosphere. The non-cancerous bladder cells, SV-HUC-1 (ATCC) were cultured in Ham's F-12K medium. When the cells reached $\sim 80 \%$ confluency, PSPA was added for the treatment of $\mathrm{BC}$. The concentrations and incubation time were stated in the following assays.

CCK-8 assay. Cell viability was estimated by a CCK-8 kit (Beyotime Institute of Biotechnology, Haimen, China) according to the manufacturer's instructions. The 5637 and T24 cells $\left(1 \times 10^{3}\right.$ cells/well) were seeded into 96-well plates, and incubated for $24 \mathrm{~h}$. According to a previous study (2), different doses of PSPA $(100,300,500,800$ and $1000 \mu \mathrm{g} / \mathrm{ml})$ were added to the culture medium. The cell viability was assessed after 24 , 48 and $72 \mathrm{~h}$. The optical density (at $450 \mathrm{~nm}$ ) was recorded with a microplate reader (Bio-Rad Laboratories, Hercules, CA, USA).

Assessement of mitochondrial membrane potential (MMP). The cells were plated at a density of $1 \times 10^{4}$ cells/well into 6-well plates, where they were cultured for $24 \mathrm{~h}$. The cells were treated with various doses of PSPA $(100,300$ and $500 \mu \mathrm{g} / \mathrm{ml})$ for $48 \mathrm{~h}$. A flow cytometry assay was employed to assess the MMP with Rhodamine123 fluorescent dye (Rho123; Sigma-Aldrich; Merck KGaA, Darmstadt, Germany). The deteriorated Rho123 accumulation in the mitochondria, indicated the collapse of the MMP. The cells were incubated with a Rho123 working solution in the dark, for $30 \mathrm{~min}$, at $37^{\circ} \mathrm{C}$. The cells were then loaded and the fluorescent signals with an emission of $525 \mathrm{~nm}$ were applied on a FACSCalibur (Becton-Dickinson, Franklin Lakes, NJ, USA).

Reactive oxygen species (ROS) content detection. The cells in each group were treated as follows: the cells were washed
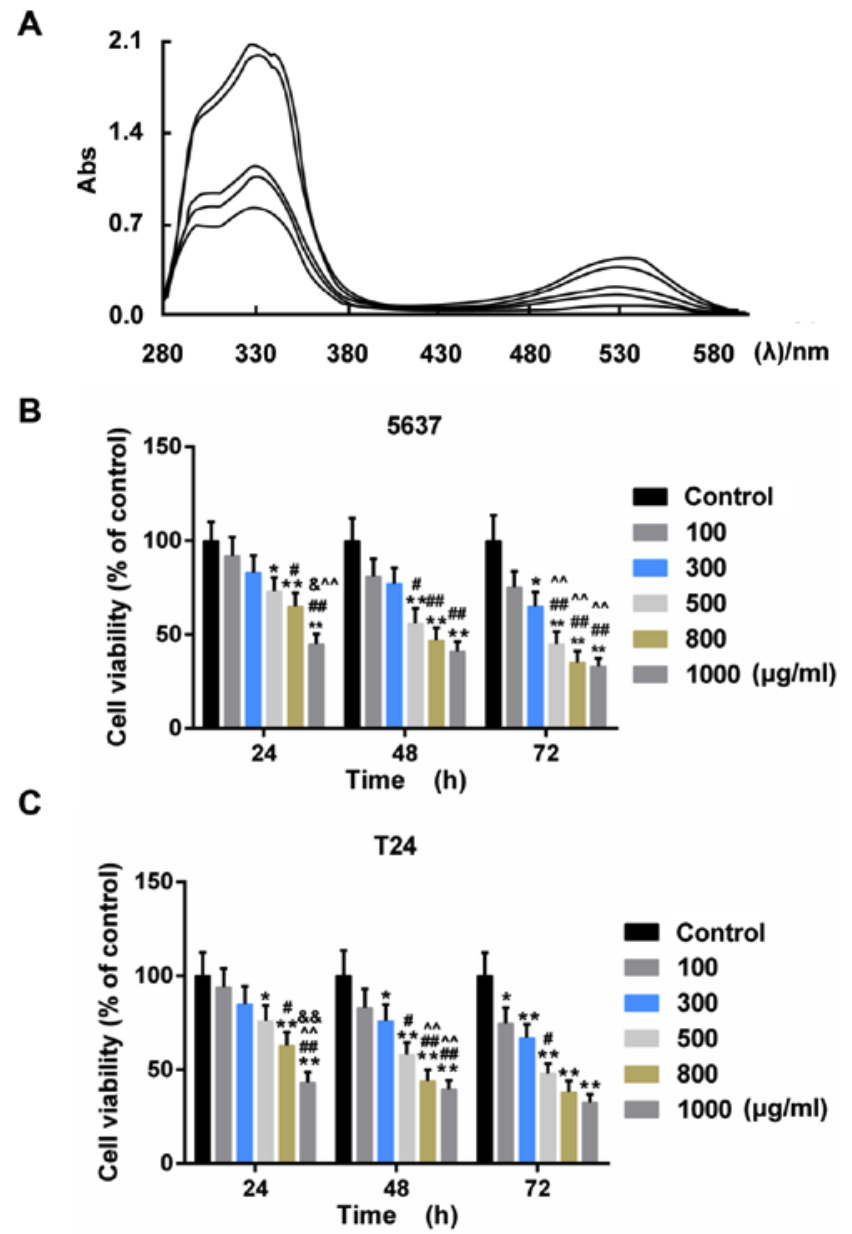

Figure 1. (A) UV-vis spectra of anthocyanins from different PSPs at 200-600 $\mathrm{nm}$. The curves in the graph denote the following PSPA extracts (from the upper to the lowest): $\mathrm{Zi} \mathrm{A1}$, Anhui $\mathrm{Zi}$, Chuanshan $\mathrm{Zi}$, Jishu 18 and $\mathrm{Zi} \mathrm{A0}$ at $330 \mathrm{~nm}$. Abs, absorption rate. (B and C) The cell viability of 5637 (B) and T24 (C) cells under treatment with PSPA at different concentrations: $100,300,500,800$ and $1,000 \mu \mathrm{g} / \mathrm{ml} ;{ }^{*} \mathrm{P}<0.05,{ }^{* *} \mathrm{P}<0.01$ vs. control (BC cells); ${ }^{\#} \mathrm{P}<0.05,{ }^{\# \#} \mathrm{P}<0.01$ vs. PSPA $100 \mu \mathrm{g} / \mathrm{ml} ;{ }^{\wedge} \mathrm{P}<0.05,{ }^{\wedge} \mathrm{P}<0.01$ vs. PSPA $300 \mu \mathrm{g} / \mathrm{ml}$; ${ }^{\&} \mathrm{P}<0.05,{ }^{\&} \mathrm{P}<0.01$ vs. PSPA $500 \mu \mathrm{g} / \mathrm{ml}$.

and then stained with fluorescent dye 2,7-dichlorofluorescein diacetate (DCFH-DA) $(10 \mu \mathrm{M})$ (Santa Cruz Biotechnology, Inc., Dallas, TX, USA) for $15 \mathrm{~min}$ at $37^{\circ} \mathrm{C}$. The DCFH-DA was transformed into the fluorescent DCF via ROS. The fluorescence intensity denoted the ROS level. The fluorescence was observed with a fluorescence plate reader (EnVision; PerkinElmer, Inc., Waltham, MA, USA).

Apoptosis detection. An Annexin V-fluorescein isothiocyanate (FITC)/propidium iodide (PI) kit (Sigma-Aldrich) was used to evaluate the apoptosis level in the BC cells. The indicated treatment with the PSPA followed. The cells were collected and washed with a PBS working buffer. The collected cells were incubated with Annexin V-FITC for $15 \mathrm{~min}$, followed by another 10 min with PI in the dark. The apoptosis rate was analyzed on a FACSCalibur, according to the manufacturer's protocol.

Cell-cycle distribution analysis. The cells were stained with a Cycletest Plus DNA Reagent kit (Becton-Dickinson). Ethanol was used to fix the cells. The cells were then incubated with RNase for $30 \mathrm{~min}$ at $37^{\circ} \mathrm{C}$. The DNA content was assessed 
A

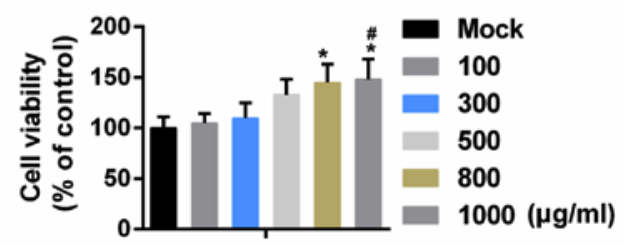

B

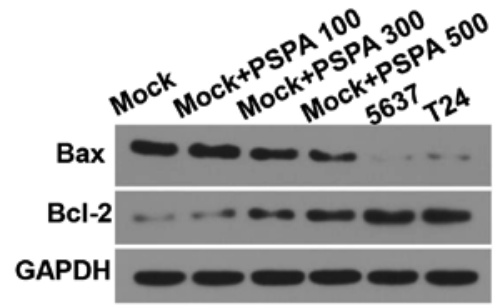

C

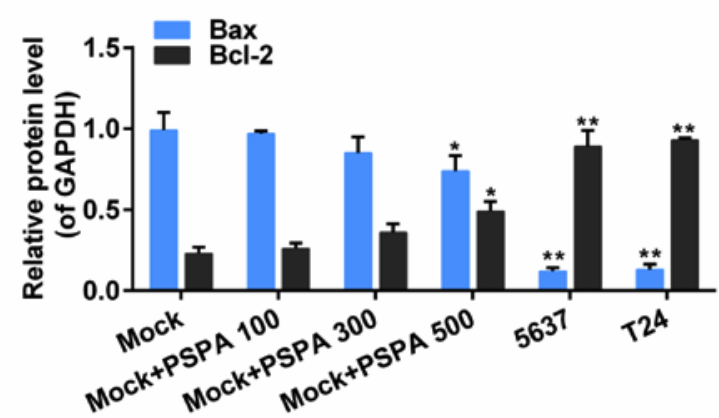

Figure 2. (A) The effect of PSPA on the viability of non-cancerous bladder cells. ${ }^{*} \mathrm{P}<0.05$ vs. mock; ${ }^{*} \mathrm{P}<0.05$ vs. PSPA $100 \mu \mathrm{g} / \mathrm{ml}$. (B and C) The expression of Bax and Bcl-2 by western blot analysis. Mock, non-cancerous bladder cells; PSPA 100/300/500 indicated cells treated with 100/300/500 $\mu \mathrm{g} / \mathrm{ml}$ PSPA, respectively; ${ }^{*} \mathrm{P}<0.05,{ }^{* *} \mathrm{P}<0.01$ vs. mock.

with a FACSCalibur, followed by PI staining for $15 \mathrm{~min}$ at room temperature. The data from at least 10,000 events in each group were acquired with CellQuest software (BectonDickinson). The percentage of the cells in each phase were presented in the results.

Real-time PCR. The cells were collected after the PSPA treatment. The total RNA was prepared from the cell cultures, using an RNA isolation kit (Takara Bio, Inc., Shiga, Japan), according to the manufacturer's instructions. The concentration of RNA was detected by NanoDrop (NanoDrop Technologies, Wilmington, DE, USA). The cDNA Synthesis kit (Takara Bio) was used to synthesize the cDNA from $2 \mu \mathrm{g}$ of RNA, according to the manufacturer's protocol. A SYBR Green PCR Master Mix (Takara Bio) was used to quantify the target gene expression level. The amplification assay was performed on Applied Biosystems ABI 7500 (Thermo Fisher Scientific, Inc). The primers used were as follows: Fas sense, 5'-GTGCTTTGCTTAGGGTTCCC-3' and antisense, 5'-AAC TTGCACTTCTGGCCATG-3'; Fasl sense, 5'-GTCCAACT CAAGGTCCATGC-3' and antisense, 5'-TTGTTGCAAGAT TGACCCCG-3'; Bcl-2-associated $\mathrm{X}$ proteins (Bax) sense, 5'-GTGCCGGAACTGATCAGAAC-3' and antisense, 5'-CCA AAGTAGGAGAGGAGGCC-3'; Bcl-2 sense, 5'-GCCTT CTTTGAGTTCGGTGG-3' and antisense, 5'-GAAATCAAA CAGAGGCCGCA-3'; cyclin B1 sense, 5' -TTGTGTGCCCA AGAAGATGC-3' and antisense, 5'-GAAGTGCAAAGGTA GAGGCC-3'; Cdc2 sense, 5'-GGAAGCTAGGGTAGTCT GGTC-3' and antisense, 5'-TCTGCAGAGTGGTTTGGT AGA-3'; GAPDH sense, 5'-CACAGTCCATGCCATCACTG-3' and antisense, 5'-ATCTCGCTCCTGGAAGATGG-3'.

Western blotting. The proteins of the collected cells were isolated with a lysis buffer containing protease inhibitors (Roche Diagnostics, Indianapolis, IN, USA). The concentra- tions of the extracted proteins were assessed with a BCA protein kit (Bio-Rad Laboratories). The proteins were denatured, separated via SDS-PAGE, and then transferred onto the PVDF membrane. The membranes were blocked with not-fatty milk and then incubated overnight with primary antibodies at $4^{\circ} \mathrm{C}$. The primary antibodies were as follows: anti-Bcl-2 (1:1,000; cat. no. ab196495; Abcam, Cambridge, MA, USA), anti-Bax (1:2,000; cat. no. ab182733; Abcam), anti-Fas (1:1,000; cat. no. ab82419; Abcam), anti-Fasl (1:200; cat. no. ab15285; Abcam), anti-cyclin B1 (1:3,000; cat. no. ab32053; Abcam), anti-Cdc2 (1:10,000; cat. no. ab133327; Abcam), anti-PI3K (1:2,000; cat. no. ab40755; Abcam), anti-phospho-PI3K (1:1,000; cat. no. ab191606; Abcam), anti-cleaved caspase-3 (1:200; cat. no. 9664; Cell Signaling Technology, Danvers, MA, USA), anti-phospho-AKT (1:2,000; cat. no. 4060; Cell Signaling Technology), anti-AKT (1:1,000; cat. no. 4685; Cell Signaling Technology) and anti-GAPDH $(1: 1,000$; cat. no. 5174; Cell Signaling Technology). Then, the secondary antibodies (horseradish peroxidase-conjugated; 1:2,000; cat. no. ab97051) were added onto the membrane and incubated for $1 \mathrm{~h}$ at room temperature. The membrane was washed and moved to ChemiDoc XRS (Bio-Rad in order to develop the protein band with an enhanced chemiluminescence reagent (GE Healthcare, Buckinghamshire, UK).

Statistical analysis. One-way analysis of variance (ANOVA) following Turkey's multiple comparison test was performed to compare the differences between the groups. Data were presented as the mean \pm standard deviation (SD). $\mathrm{P}<0.05$ was considered to indicate a statistically significant difference.

\section{Results}

The effect of PSPA on the viability of BC cells. The acylanthocyanin structure in PSP caused the extracts to have a 
A

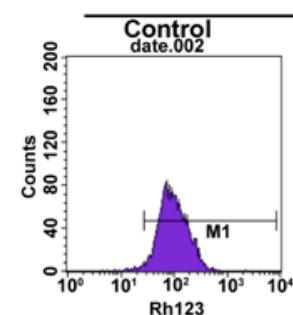

B

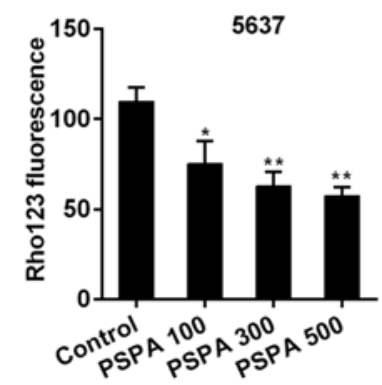

5637

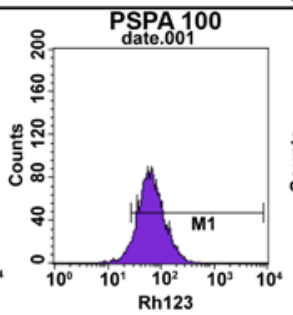

C

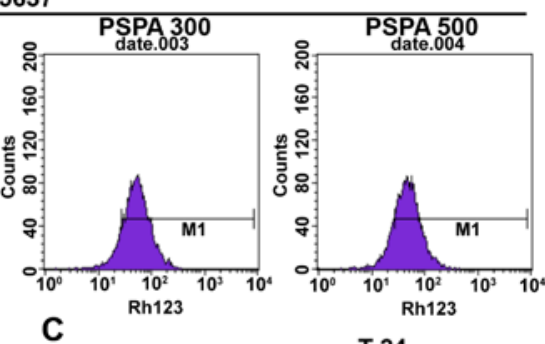

C

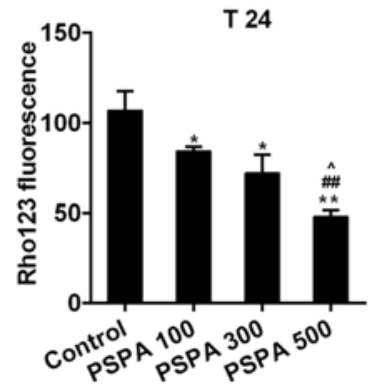

D

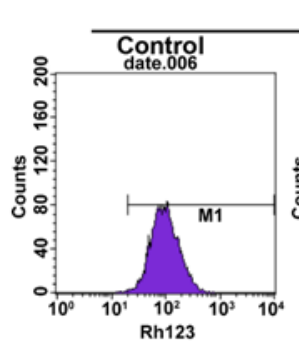

E

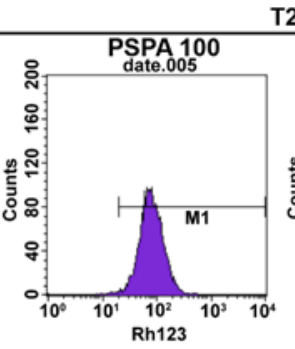

5637

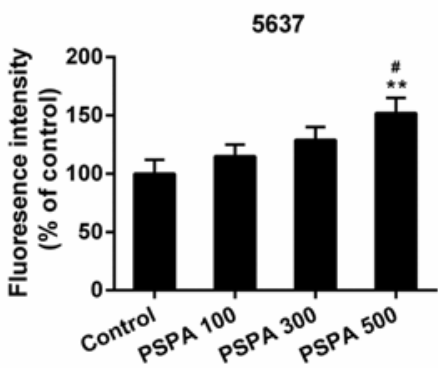

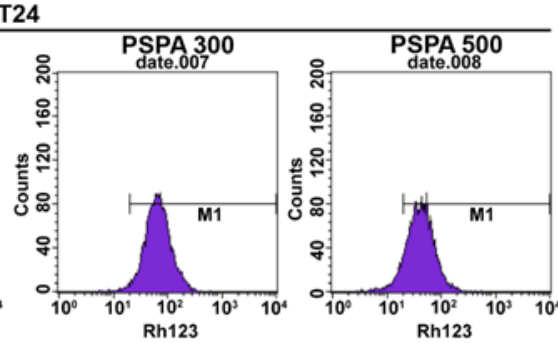

$\mathbf{F}$
T 24

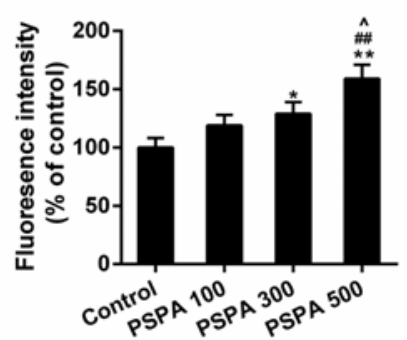

Figure 3. (A and B) Flow cytometry for the detection of MMP by collecting the Rho123 fluorescent signals in the 5637 cells. (C and D) The detection of MMP in T24 cells by flow cytometry. (E and F) ROS determination by DCHF-DA. Control, BC cells; PSPA 100/300/500 indicated cells treated with 100/300/500 $\mu \mathrm{g} / \mathrm{ml}$ PSPA, respectively. ${ }^{*} \mathrm{P}<0.05,{ }^{* *} \mathrm{P}<0.01$ vs. the control; ${ }^{\#} \mathrm{P}<0.05$ vs. PSPA $100 ;{ }^{\# \#} \mathrm{P}<0.01$ vs. PSPA $100 ;{ }^{\wedge} \mathrm{P}<0.05,{ }^{\wedge} \mathrm{P}<0.01$ vs. PSPA 300 .

strong absorption peak approximately $330 \mathrm{~nm}$ (Fig. 1A). The absorbance value in the visible region (approximately $530 \mathrm{~nm}$ ) ranged from 0.2-0.4 contingent on the different PSPA types. The PSPA from the $\mathrm{Zi} \mathrm{A} 1$ extract had the highest concentration of anthocyanins (76.63 mg/100 g Fw) and the highest absorbance value. Therefore, the PSPA from $\mathrm{Zi} \mathrm{A} 1$ was selected for the subsequent experiments. The effect of PSPA on BC cell lines, 5637and T24, was determined. The results revealed that the viability of the $\mathrm{BC}$ cells decreased as the PSPA treatment concentrations increased. The inhibition rate of the PSPA at $800 \mu \mathrm{g} / \mathrm{ml}$ was $>60 \%$ after a 72 -h incubation (Fig. 1B). PSPAs at concentrations of 100,300 and $500 \mu \mathrm{g} / \mathrm{ml}$ were chosen to explore the function of PSPA in BC cells.

The effect of PSPA on cell viability and apoptosis in noncancerous bladder cells. To estimate the effect of PSPA on non-cancerous bladder cells, the cell viability and apoptosis was assessed. It was revealed that, after 48-h incubation with PSPA, the viability of non-cancerous cells was improved and the non-cancerous cells exhibited an elevated Bcl-2/Bax ratio. Furthermore, the $\mathrm{Bcl}-2 / \mathrm{Bax}$ ratio was more obvious in $\mathrm{BC}$ cells (Fig. 2). It was indicated that the PSPA treatment did not decrease the cell proliferation of non-cancerous cells and it presented proliferation promotion effects to some extent.

PSPA enhanced the collapse of MMP and ROS accumulation of $B C$ cells. Mitochondria are deeply involved in cell death. The collapse of mitochondrial membrane potential (MMP) is the hallmark step in the progression of cell apoptosis. The loss of the MMP induces the ROS-mediated oxidative stress (22). The MMP and the ROS content were assessed to detect whether the PSPA caused oxidative stress in the BC cells. The results displayed in Fig. 3A-D demonstrated that the Rho123 staining fluorescence was reduced by the PSPA in a dose-dependent 
A

5637
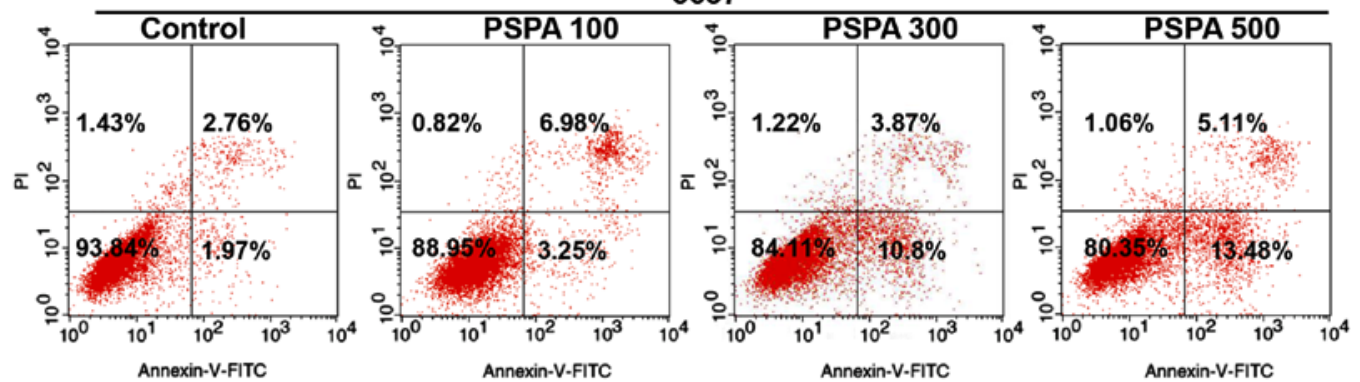

B

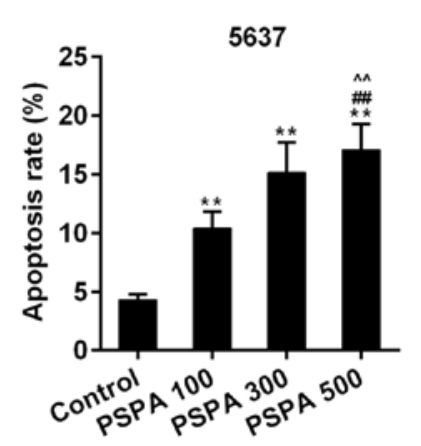

C

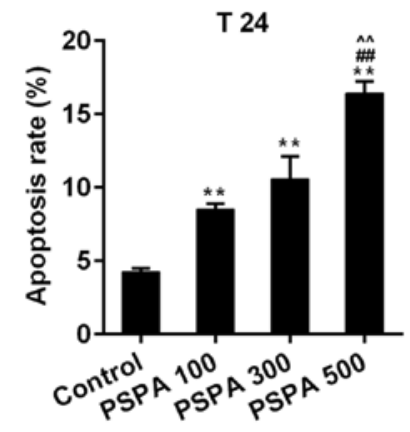

D
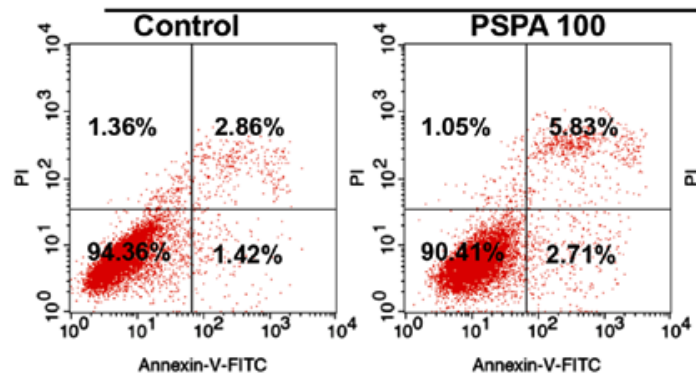

T 24
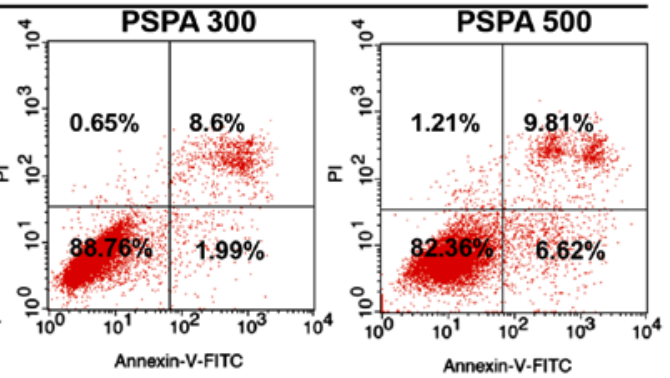

Figure 4. (A and B) Annexin V-FITC/PI dye was employed in flow cytometry analysis for the detection of apoptosis in 5637 cells. (C and D) The detection of apoptosis in T24 cells. Control, BC cells; PSPA 100/300/500 indicated cells treated with $100 / 300 / 500 \mu \mathrm{g} / \mathrm{ml} \mathrm{PSPA}$, respectively; ${ }^{* *} \mathrm{P}<0.01 \mathrm{vs}$. control; ${ }^{\# \#} \mathrm{P}<0.01$ vs. PSPA $100 ;{ }^{\wedge} \mathrm{P}<0.05$ vs. PSPA 300.

manner. The ROS content in 5637 and T24 cells gradually increased after the PSPA treatment (Fig. 3E-F).

PSPA triggered apoptosis and cell cycle arrest of BC cells. The apoptosis rate and cell cycle progression of BC cells were assessed in order to confirm the effect of PSPA on BC cells. The results from flow cytometry revealed that the marked apoptosis of 5637 and T24 cells was triggered by the dosedependent PSPA treatment (Fig. 4). The cell cycle checkpoint has been widely accepted to be linked to cancer. The cell cycle distribution after the treatment of PSPA was determined. It can be noticed that a climb in the proportion of S-phase cells, a decrease in G1-phase cells and an increase in the G2/M phase. Among these changes, the proportions of cells in the G2/M phase were increased in an almost linear manner (Fig. 5).

The effect of PSPA on the expression of apoptotic and cell cycle related proteins. The expression of the apoptosis-related genes was estimated in order to investigate the mechanisms by which PSPA enhanced the sensitivity to apoptosis of the $\mathrm{BC}$ cells. The results revealed that the expression of the pro- apoptotic genes (Fas, Fasl and Bax) and the anti-apoptotic gene (Bcl-2) was elevated and then weakened by the PSPA in the transcriptional level (Fig. 6A and B). Cyclin B1 and Cdc2 are important cyclin regulatory proteins in the $\mathrm{G} 2 / \mathrm{M}$ checkpoint (23). The mRNA expression of these two proteins was downregulated in the PSPA groups compared to the control group both in the transcriptional and translational levels (Fig. 6C and D). The expression of these apoptosis- and cell cycle-associated proteins was consistent within the mRNA level. The expression of cleaved caspase- 3 was higher in the PSPA treatment groups (Fig. 7).

PSPA inhibited the PI3K/Akt signaling pathway in BC cells. $\mathrm{PI} 3 \mathrm{~K} / \mathrm{Akt}$ signaling is an important signaling pathway in the cell cycle regulation, where it is directly related to cancer (16). As displayed in Fig. 8, the PSPA treatment activated the expression of $\mathrm{p}$-PI3K and $\mathrm{p}$-Akt in the non-cancerous bladder cells. Furthermore, the activity of PI3K/Akt was elevated in the BC cells compared to the non-cancerous bladder cells. By contrast, the phosphorylation of PI3K was suppressed by the PSPA pre-treatment. The expression of the total PI3K was not 


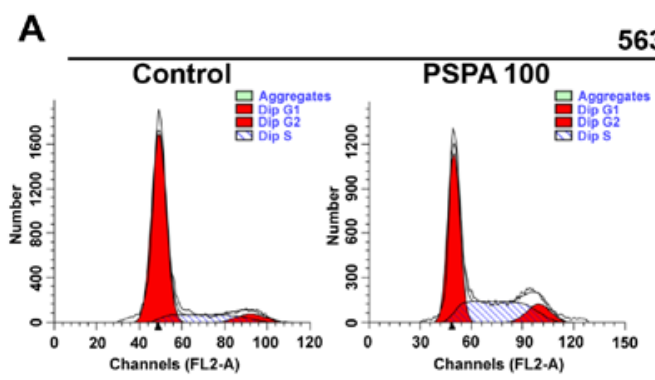

5637

B

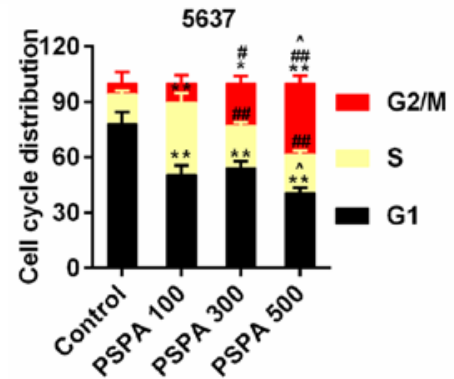

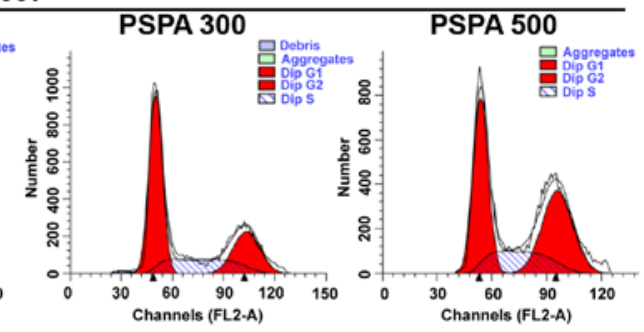

C

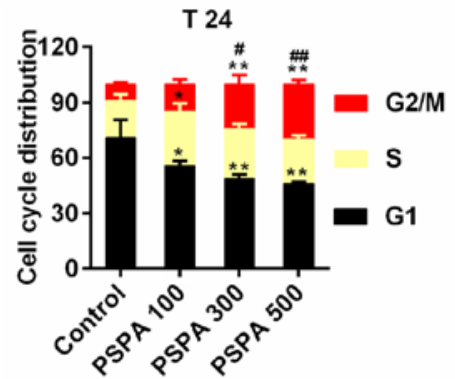

D

T24

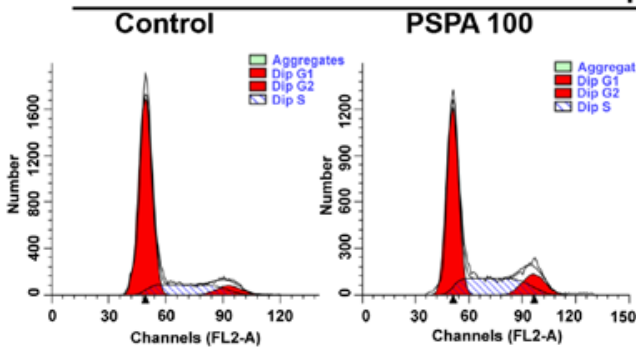

PSPA 300

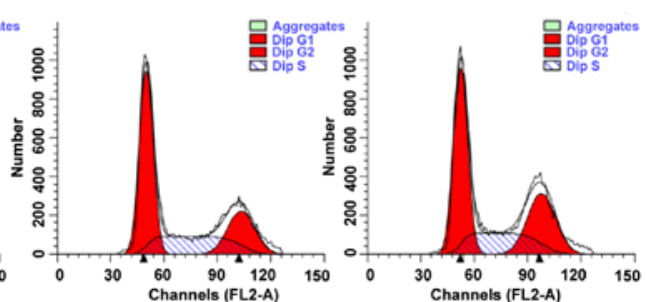

Figure 5. (A and B) Flow cytometry for the estimation of the cell cycle distribution of 5637 cells. (C and D) Cell cycle distribution of T24 cells using flow cytometry assay. Control, BC cells; PSPA 100/300/500 indicated cells treated with 100/300/500 $\mu \mathrm{g} / \mathrm{ml} \mathrm{PSPA}$, respectively; $\mathrm{P}<0.05,{ }^{* *} \mathrm{P}<0.01 \mathrm{vs}$. control; ${ }^{\#} \mathrm{P}<0.05,{ }^{\# \#} \mathrm{P}<0.01$ vs. PSPA 100; ${ }^{\wedge} \mathrm{P}<0.05,{ }^{\wedge} \mathrm{P}<0.01$ vs. PSPA 300.

A

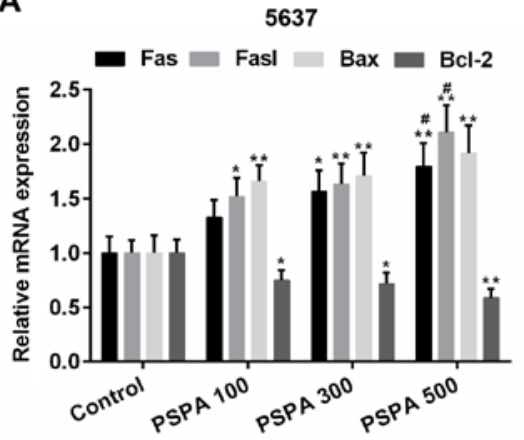

C

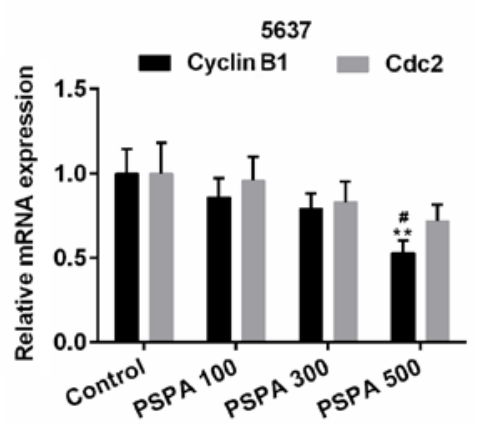

B

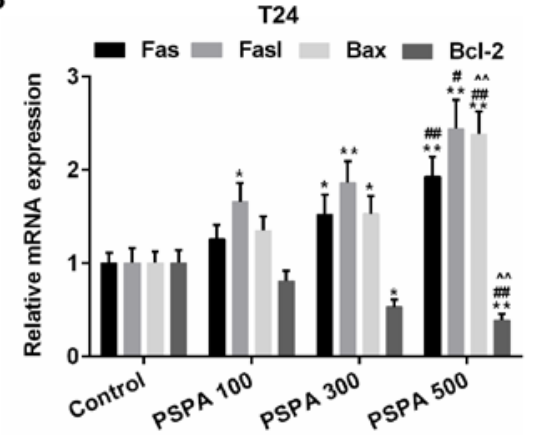

D

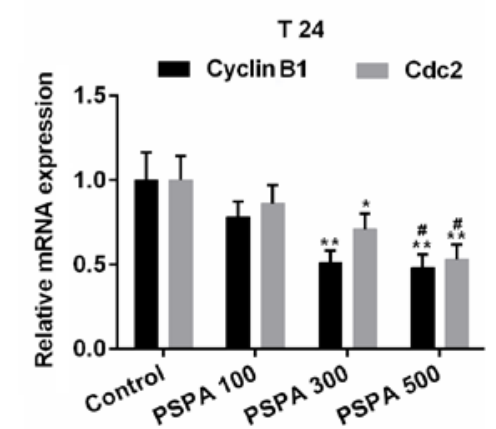

Figure 6. (A and B) RT-PCR for the quantification of the expression of Fas, Fasl, Bax and Bcl-2 in 5637 (A) and T24 (B) cells. (C and D) RT-PCR for the quantification of the expression of cyclin B1and Cdc2 in 5637 (C) and T24 (D) cells. Control, BC cells; PSPA 100/300/500 indicated cells treated with $100 / 300 / 500 \mu \mathrm{g} / \mathrm{ml}$ PSPA, respectively; ${ }^{*} \mathrm{P}<0.05,{ }^{* *} \mathrm{P}<0.01$ vs. control; ${ }^{\#} \mathrm{P}<0.05,{ }^{\# \#} \mathrm{P}<0.01$ vs. PSPA $100 ;{ }^{\wedge} \mathrm{P}<0.05,{ }^{\wedge} \mathrm{P}<0.01$ vs. PSPA 300. 
A

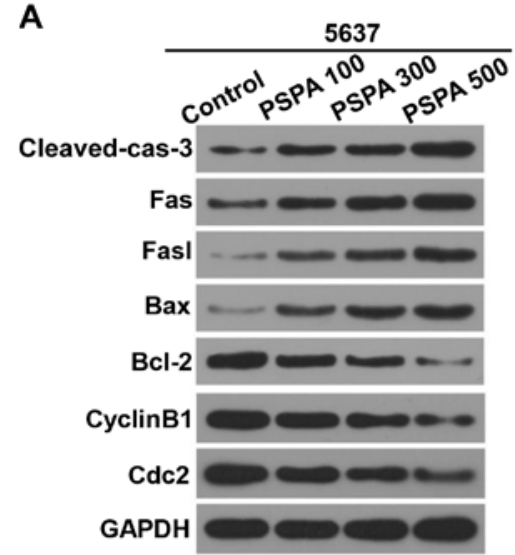

B

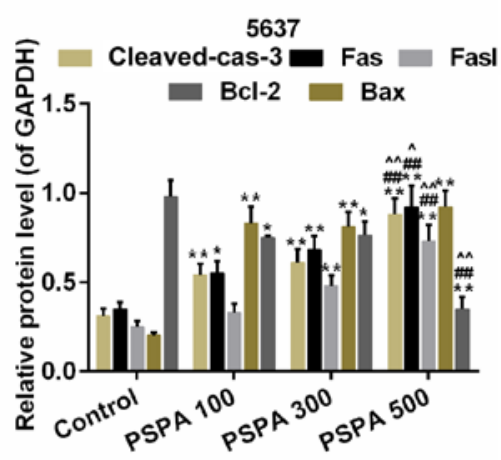

C

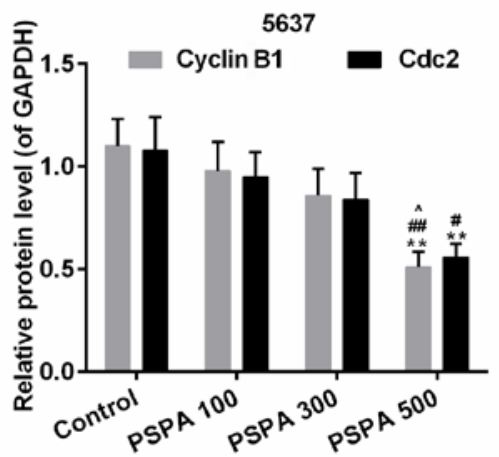

D

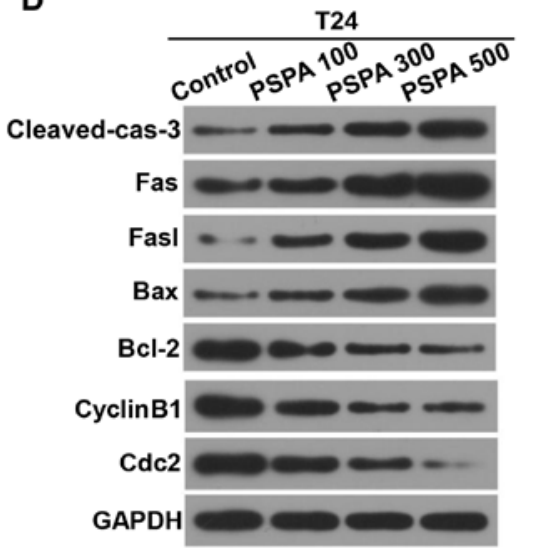

E

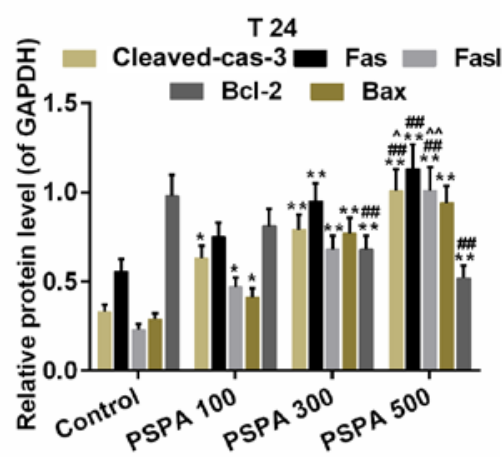

F

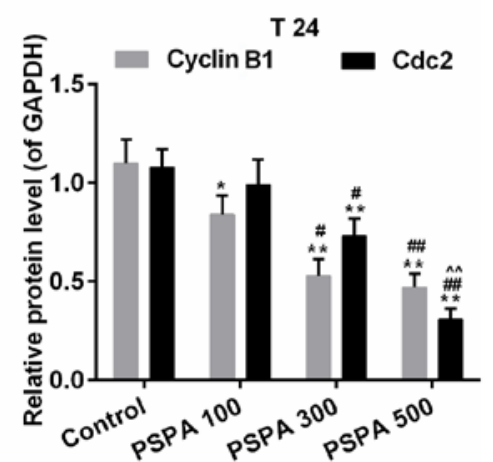

Figure 7. Western blot analysis and determination of the expression of cleaved caspase-3, Fas, Fasl, Bax, Bcl-2, cyclin B1and Cdc2 in 5637 (A-C) and T24 (D-F) cells. Cleaved-cas-3, cleaved caspase-3; Control, BC cells; PSPA 100/300/500 indicated cells treated with 100/300/500 $\mu \mathrm{g} / \mathrm{ml}$ PSPA, respectively; ${ }^{*} \mathrm{P}<0.05$, ${ }^{* *} \mathrm{P}<0.01$ vs. control; ${ }^{\#} \mathrm{P}<0.05,{ }^{\# \#} \mathrm{P}<0.01$ vs. PSPA $100 ;{ }^{\wedge} \mathrm{P}<0.05,{ }^{\wedge} \mathrm{P}<0.01$ vs. PSPA 300.

influenced. The phosphorylation of its downstream substrate, Akt, was inhibited by the PSPA. The expression of the total Akt was not altered.

\section{Discussion}

In the present study, we observed a strong absorption peak approximately $330 \mathrm{~nm}$ that indicated the profound distribution of acylated anthocyanins in PSP, especially PSPA from Zi A1. The results in the present study proved that PSPA inhibited the cell viability of BC cells in a dose-dependent manner. By contrast, PSPA exhibited an opposite effect in non-cancerous cells by enhancing cell viability and resistance to apoptosis. Furthermore, according to previous studies, PSPA was capable of inhibiting the proliferation in multiple cell types (24), while the proliferation and anti-apoptotic effect of PSPA has also been reported $(25,26)$. The reason for this appeared contradictory effect was not very clear. It may have been influenced by the intracellular microenvironments.

The present study focused on the antitumor effect of PSPA. However, the effect of the anthocyanins in these studies was attributed to the non-acylated anthocyanins. There was a strong absorption peak approximately $330 \mathrm{~nm}$, which indicated the distribution of the acylated anthocyanins in the PSPA, particularly the PSPA from $\mathrm{Zi} \mathrm{A} 1$. We observed that the PSPA inhibited the BC cell viability in a dose-dependent manner. This effect was largely attributed to the acylated anthocyanins in PSPA, which was supported by a previous study (27). Caffeic and ferulic acid also demonstrated anti-proliferative abilities in cancer cells $(28,29)$, therefore, coffeoyl and feruloyl in PSPA provided the beneficial antitumor effect. Anthocyanins are first metabolized by the gut microflora, leading to anthocyanidin metabolites $(30,31)$. It was uncertain whether the anthocyanins were metabolized 
A

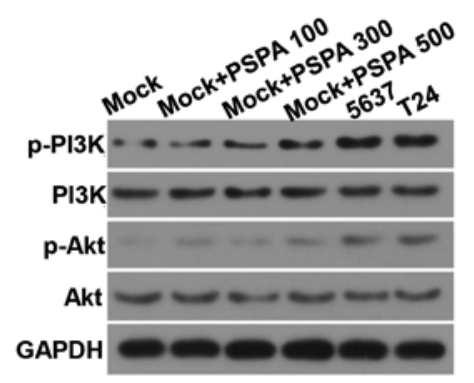

C

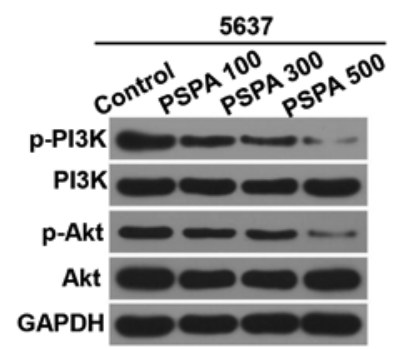

D

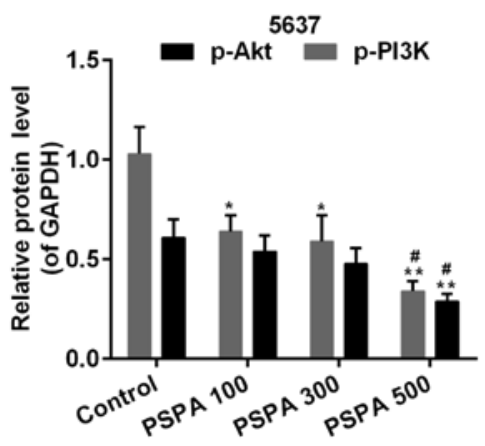

B

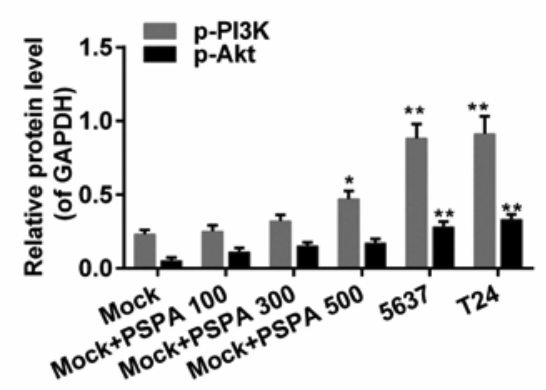

E

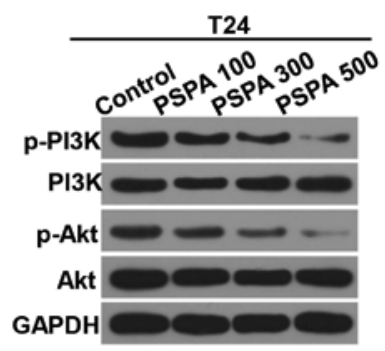

$\mathbf{F}$

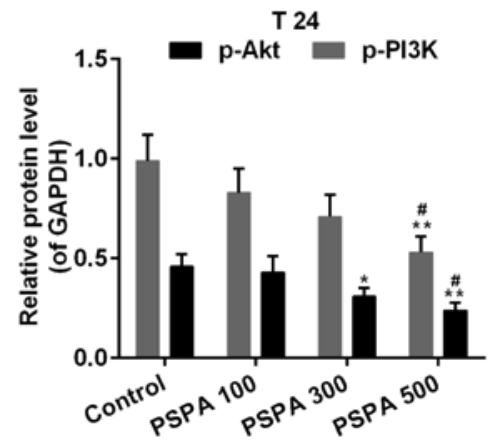

Figure 8. (A and B) Western blot analysis and determination of the expression of PI3K, p-PI3K, Akt, and p-Akt in non-cancerous bladder cells; Mock, non-cancerous bladder cells; ${ }^{*} \mathrm{P}<0.05,{ }^{* *} \mathrm{P}<0.01$ vs. mock. (C-F) Western blot analysis and determination of the expression of PI3K, p-PI3K, Akt, and p-Akt in 5637 (A and B) and T24 (C and D) cells. Control, BC cells; PSPA 100/300/500 indicated cells treated with 100/300/500 $\mu \mathrm{g} / \mathrm{ml} \mathrm{PSPA}$, respectively; ${ }^{*} \mathrm{P}<0.05$, ${ }^{* *} \mathrm{P}<0.01$ vs. control; ${ }^{*} \mathrm{P}<0.05$ vs. PSPA 100.

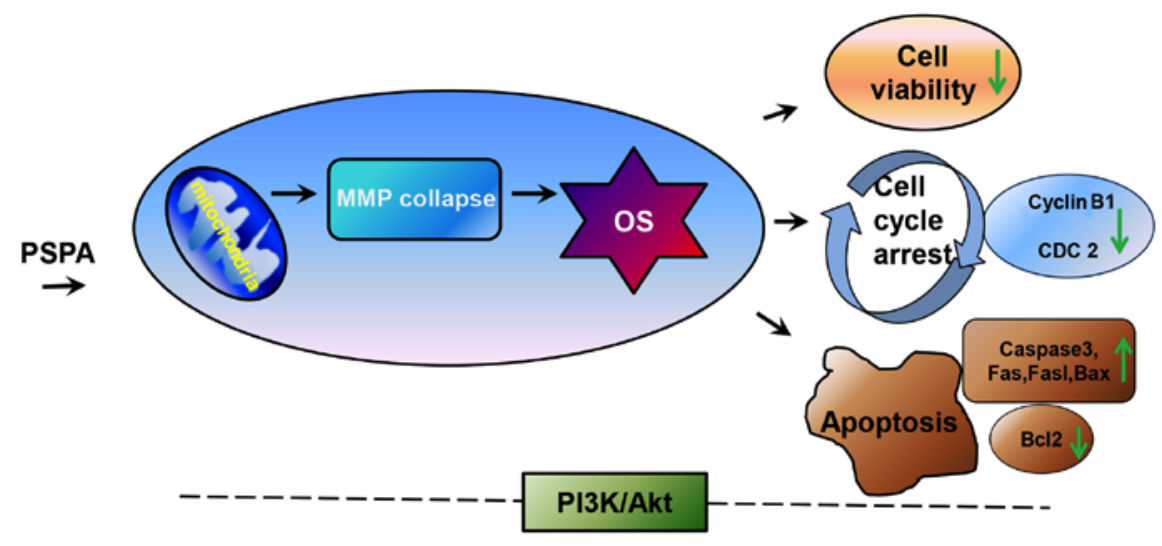

Figure 9. The speculated work model of the present study. Mitochondria may be the first target of PSPA in cells. Then the dysfunction of mitochondria (loss of MMP, ROS burst) induces oxidative stress, thereby decreasing cell viability, inducing apoptosis and cell cycle arrest. In addition, PI3K/Akt is involved in this process, though the definite mechanism is not clear. MMP, mitochondrial membrane potential; OS, oxidative stress; caspase-3, cleaved caspase-3.

into anthocyanidins or other metabolites within this study model. The exact molecules (anthocyanins, anthocyanidins or their combined effect) that exerted this cancer prevention effect were unclear in the present study.
Furthermore, the collapse of the MMP and the ROS content were enhanced by the PSPA treatment. Oxidative stress was subsequently triggered, which was closely related to cell survival (32). The growth inhibitory effect of PSPA could be 
attributed to the overload of ROS in BC cells. This was in agreement with some cancer cell studies $(13,14)$. There were studies that reported a promotion effect of PSPA on cell viability $(25,33)$. The anthocyanins appeared to have a paradoxical role in the generation of the ROS (34-36). These contradictory results could be caused by the different cell redox status, the cell types and the concentration employed, which would lead to different cell fates.

The anti-proliferation ability could be modulated by the induction of apoptosis. Mitochondria have been implicated in apoptosis (37). Mitochondria dysfunction triggers the dissipation of MMP, the release of caspase-activating factors and finally leads to the activation of apoptosis cascades (38). The apoptosis of BC cells was aggravated by PSPA. On the contrary, cell cycle arrest is another common cancer prevention strategy. The effect of PSPA on cell cycle arrest was further evaluated. The data in the present study indicated that PSPA induced the G2/M arrest of the BC cells. The G2/M checkpoint is a DNA-damage checkpoint in cell cycle regulation, which suppresses the progression of the cell cycle (23). This checkpoint was used to prevent tumor growth and to induce the apoptosis of tumor cells. Thus, PSPA was able to suppress the growth of BC cells by inducing cell cycle arrest.

Many molecules have been identified as participants in the apoptosis cascades, which either promote or inhibit apoptosis. For instance, Bcl-2 is an anti-apoptotic molecule, while the Fas/Fasl and Bcl-2-associated X protein (Bax) are pro-apoptotic molecules $(39,40)$. The activation of caspase-3 is the convergence of multiple apoptosis signaling (41). The expression of the proapoptotic genes (Fas, Fasl, and Bax) and the anti-apoptotic gene (Bcl-2) was induced and suppressed by the PSPA. The PSPA enhanced the activity of caspase- 3 and increased the BC cell apoptosis. This effect was partly due to the inhibitory effect of PSPA on cell viability. In addition, the expression of regulatory proteins, cyclin B1 and $\mathrm{Cdc} 2$ that were involved in the G2/M checkpoint was evaluated to confirm the effect of PSPA. The degradation of cyclin B1 and Cdc2 would promote the G2/M arrest, which could be a treatment option for tumor suppression (42). The results revealed that the expression of cyclin B1 and $\mathrm{Cdc} 2$ was downregulated by PSPA. These results indicated that PSPA inhibited tumor growth, enhanced the sensitivity to apoptosis and induced the G2/M arrest of the BC cells.

PI3K/Akt is an important mechanism for controlling cell growth and proliferation (16). The PSPA was suggested to activate the PI3K/Akt signaling in some study models $(43,44)$. The data in the present study revealed that the activity of PI3K and Akt was mitigated in the PSPA treatment group. This result seemed to be conflicting to the effect of the PSPA. However, hyperactivation of the PI3K/Akt signaling is common in cancer $(45,46)$. Therefore, the decreased activity of the PI3K/Akt signaling could be favorable for cancer prevention. This could depend on the cell types and cell context (47). These observations support the beneficial effect of PSPA. Collectively, the antitumor effect of PSPA was proved in $\mathrm{BC}$ cells. According to the work model scheme displayed in Fig. 9, after the treatment of PSPA, the mitochondria in BC cells were dysregulated and then serious oxidative stress was triggered. Under this excessive oxidative stress, the cell viability was reduced, the cell cycle was arrested and apoptosis was induced in BC cells. Although the exact regulation mechanism needed further investigation, our results revealed that the inhibition of PI3K/Akt was associated with the protective effect of PSPA. Furthermore, the antitumor effect of PSPA was gathered from the in vitro data. This was another limitation of the present study. It is necessary to confirm the antitumor effect within further in vivo studies. The combination administration of the current chemotherapeutic drug with the PSPA could bring an intriguing effect in protection against $\mathrm{BC}$.

The current study demonstrated that PSPA exerted an antitumor effect in BC cells through the suppression of cell viability, the aggravation of MMP collapse, the promotion of apoptosis and the induction of cell cycle arrest, which could be related to the suppression of the PI3K/Akt signaling. The data in the present study were an in vitro analysis and this study seems to be the first preclinical study that illustrated the effect of PSPA in BC. The present study shed light on a possible antitumor agent as a treatment option for BC.

\section{Acknowledgements}

Not applicable.

\section{Funding}

The present study was supported by the Zhejiang Provincial Health Department (grant no. 2014ZB135).

\section{Availability of data and materials}

The datasets used during the present study are available from the corresponding author upon reasonable request.

\section{Authors' contributions}

WLL and TH conceived and designed the study. HYY, XJZ and MK performed the experiments. WLL wrote the study. WLL, HYY, XJZ and TH reviewed and edited the manuscript. All authors read and approved the manuscript and agree to be accountable for all aspects of the research in ensuring that the accuracy or integrity of any part of the work are appropriately investigated and resolved.

\section{Ethics approval and consent to participate}

Not applicable.

\section{Consent for publication}

Not applicable.

\section{Competing interests}

The authors declare that they have no competing interests.

\section{References}

1. Jemal A, Siegel R, Ward E, Hao Y, Xu J, Murray T and Thun MJ: Cancer statistics, 2008. CA Cancer J Clin 58: 71-96, 2008.

2. Parkin DM, Bray F, Ferlay J and Pisani P: Global cancer statistics, 2002. CA Cancer J Clin 55: 74-108, 2005.

3. Wu X, Ros MM, Gu J and Kiemeney L: Epidemiology and genetic susceptibility to bladder cancer. BJU Int 102: 1207-1215, 2008.

4. Zeegers MP, Tan FE, Dorant E and van Den Brandt PA: The impact of characteristics of cigarette smoking on urinary tract cancer risk: A meta-analysis of epidemiologic studies. Cancer 89: 630-639, 2000 
5. Rödel C, Grabenbauer GG, Kühn R, Papadopoulos T, Dunst J, Meyer M, Schrott KM and Sauer R: Combined-modality treatment and selective organ preservation in invasive bladder cancer: Long-term results. J Clin Oncol 20: 3061-3071, 2002.

6. Kaufman DS, Shipley WU and Feldman AS: Bladder cancer. Lancet 374: 239-249, 2009.

7. Hanneken A, Lin FF, Johnson J and Maher P: Flavonoids protect human retinal pigment epithelial cells from oxidative-stressinduced death. Invest Ophthalmol Vis Sci 47: 3164-3177, 2006.

8. Zhang ZF, Fan SH, Zheng YL, Lu J, Wu DM, Shan Q and Hu B: Purple sweet potato color attenuates oxidative stress and inflammatory response induced by d-galactose in mouse liver. Food Chem Toxicol 47: 496-501, 2009.

9. Shindo M, Kasai T, Abe A and Kondo Y: Effects of dietary administration of plant-derived anthocyanin-rich colors to spontaneously hypertensive rats. J Nutr Sci Vitaminol (Tokyo) 53: 90-93, 2007.

10. Zhao JG, Yan QQ, Lu LZ and Zhang YQ: In vivo antioxidant, hypoglycemic, and anti-tumor activities of anthocyanin extracts from purple sweet potato. Nutr Res Pract 7: 359-365, 2013.

11. Suda I, Oki T, Masuda M, Nishiba Y, Furuta S, Matsugano K, Sugita $\mathrm{K}$ and Terahara N: Direct absorption of acylated anthocyanin in purple-fleshed sweet potato into rats. J Agric Food Chem 50: 1672-1676, 2002.

12. Harada K, Kano M, Takayanagi T, Yamakawa $O$ and Ishikawa $F$. Absorption of acylated anthocyanins in rats and humans after ingesting an extract of Ipomoea batatas purple sweet potato tuber. Biosci Biotechnol Biochem 68: 1500-1507, 2004.

13. Hagiwara A, Yoshino H, Ichihara T, Kawabe M, Tamano S, Aoki H, Koda T, Nakamura M, Imaida K, Ito N, et al: Prevention by natural food anthocyanins, purple sweet potato color and red cabbage color, of 2-amino-1-methyl-6-phenylimidazo[4,5-b] pyridine (PhIP)-associated colorectal carcinogenesis in rats initiated with 1,2-dimethylhydrazine. J Toxicol Sci 27: 57-68, 2002.

14. Lim S, Xu J, Kim J, Chen TY, Su X, Standard J, Carey E, Griffin J, Herndon B, Katz B, et al: Role of anthocyanin-enriched purple-fleshed sweet potato $\mathrm{p} 40$ in colorectal cancer prevention. Mol Nutr Food Res 57: 1908-1917, 2013.

15. Hayashi K, Hibasami H, Murakami T, Terahara N, Mori M and Tsukui A: Induction of apoptosis in cultured human stomach cancer cells by potato anthocyanins and its inhibitory effects on growth of stomach cancer in mice. Food Sci Technol Res 12: 22-26, 2006

16. Cantley LC: The phosphoinositide 3-kinase pathway. Science 296: 1655-1657, 2002.

17. Luo J, Manning BD and Cantley LC: Targeting the PI3K-Akt pathway in human cancer: Rationale and promise. Cancer Cell 4 257-262, 2003

18. Shaw RJ and Cantley LC: Ras, PI(3)K and mTOR signalling controls tumour cell growth. Nature 441: 424-430, 2006.

19. Philp AJ, Campbell IG, Leet C, Vincan E, Rockman SP Whitehead RH, Thomas RJ and Phillips WA: The phosphatidylinositol 3'-kinase p85alpha gene is an oncogene in human ovarian and colon tumors. Cancer Res 61: 7426-7429, 2001.

20. Parsons DW, Wang TL, Samuels Y, Bardelli A, Cummins JM, DeLong L, Silliman N, Ptak J, Szabo S, Willson JK, et al: Colorectal cancer: Mutations in a signalling pathway. Nature 436: 792,2005

21. Liu X, Mu T, Sun H, Zhang M and Chen J: Optimisation of aqueous two-phase extraction of anthocyanins from purple sweet potatoes by response surface methodology. Food Chem 141: 3034-3041, 2013

22. Yang LJ, Zhu LX, Dong WR, Cao YL, Wang K, Huang HQ, Rong ZJ; Department of Orthopaedics, Zhujiang Hospital, Southern Medical University: Changes of ROS and mitochondrial transmembrane potential in oxidative stressinduced apoptosis in nucleus pulposus cells of rats. J Pract Med 2: 2014 (In Chinese). http://en.cnki.com.cn/Article_en/ CJFDTOTAL-SYYZ201402011.htm

23. Yao YB, Peng ZG, Liu ZF, Yang J and Luo J: Effects of mangiferin on cell cycle status and CDC2/Cyclin B1 expression of HL-60 cells. Zhong Yao Cai 33: 81-85, 2010 (In Chinese).

24. Matsunaga $N$, Tsuruma $K$, Shimazawa M, Yokota $S$ and Hara $H$ Inhibitory actions of bilberry anthocyanidins on angiogenesis. Phytother Res 24 (Suppl 1): S42-S47, 2010.

25. Sun M, Lu X, Hao L, Wu T, Zhao H and Wang C: The influences of purple sweet potato anthocyanin on the growth characteristics of human retinal pigment epithelial cells. Food Nutr Res 59: 27830,2015
26. Shih PH, Yeh CT and Yen GC: Anthocyanins induce the activation of phase II enzymes through the antioxidant response element pathway against oxidative stress-induced apoptosis. J Agric Food Chem 55: 9427-9435, 2007.

27. Lu X, Sun M, Hao L, Wu T, Zhao H and Wang C: Purple sweet potato anthocyanin inhibits the proliferation of human retinal pigment epithelial cell by blocking cell cycle and inducing apoptosis. Adv J Food Sci Technol 11: 561-569, 2016.

28. Serafim TL, Carvalho FS, Marques MP, Calheiros R, Silva T, Garrido J, Milhazes N, Borges F, Roleira F, Silva ET, et al: Lipophilic caffeic and ferulic acid derivatives presenting cytotoxicity against human breast cancer cells. Chem Res Toxicol 24: 763-774, 2011.

29. Eitsuka T, Tatewaki N, Nishida H, Kurata T, Nakagawa K and Miyazawa T: Synergistic inhibition of cancer cell proliferation with a combination of $\delta$-tocotrienol and ferulic acid. Biochem Biophys Res Commun 453: 606-611, 2014.

30. Felgines C, Texier O, Besson C, Fraisse D, Lamaison JL and Rémésy C: Blackberry anthocyanins are slightly bioavailable in rats. J Nutr 132: 1249-1253, 2002.

31. Tsuda T, Horio F and Osawa T: Absorption and metabolism of cyanidin 3-O-beta-D-glucoside in rats. FEBS Lett 449: 179-182, 1999.

32. Brieger K, Schiavone S, Miller FJ Jr and Krause KH: Reactive oxygen species: From health to disease. Swiss Med Wkly 142: w13659, 2012.

33. Ye J, Meng X, Yan C and Wang C: Effect of purple sweet potato anthocyanins on beta-amyloid-mediated PC-12 cells death by inhibition of oxidative stress. Neurochem Res 35: 357-365, 2010.

34. Cvorovic J, Tramer F, Granzotto M, Candussio L, Decorti G and Passamonti S: Oxidative stress-based cytotoxicity of delphinidin and cyanidin in colon cancer cells. Arch Biochem Biophys 501: 151-157, 2010.

35. Feng R, Ni HM, Wang SY, Tourkova IL, Shurin MR, Harada H and Yin XM: Cyanidin-3-rutinoside, a natural polyphenol antioxidant, selectively kills leukemic cells by induction of oxidative stress. J Biol Chem 282: 13468-13476, 2007.

36. Schumacker PT: Reactive oxygen species in cancer cells: Live by the sword, die by the sword. Cancer Cell 10: 175-176, 2006.

37. Kaul M, Garden GA and Lipton SA: Pathways to neuronal injury and apoptosis in HIV-associated dementia. Nature 410: 988-994, 2001.

38. Jeong SY and Seol DW: The role of mitochondria in apoptosis. BMB Rep 41: 11-22, 2008.

39. Villa-Morales M and Fernández-Piqueras J: Targeting the Fas/ FasL signaling pathway in cancer therapy. Expert Opin Ther Targets 16: 85-101, 2012.

40. Gil-Gómez G, Berns A and Brady HJ: A link between cell cycle and cell death: Bax and $\mathrm{Bcl}-2$ modulate $\mathrm{Cdk} 2$ activation during thymocyte apoptosis. EMBO J 17: 7209-7218, 1998.

41. Harada J and Sugimoto M: Activation of caspase-3 in betaamyloid-induced apoptosis of cultured rat cortical neurons. Brain Res 842: 311-323, 1999.

42. Wang HC, Pao J, Lin SY and Sheen LY: Molecular mechanisms of garlic-derived allyl sulfides in the inhibition of skin cancer progression. Ann NY Acad Sci 1271: 44-52, 2012.

43. Lu J, Wu DM, Zheng YL, Hu B and Zhang ZF: Purple sweet potato color alleviates D-galactose-induced brain aging in old mice by promoting survival of neurons via PI3K pathway and inhibiting cytochrome C-mediated apoptosis. Brain Pathol 20: 598-612,2010.

44. Zhang ZF, Lu J, Zheng YL, Hu B, Fan SH, Wu DM, Zheng ZH, Shan $Q$ and Liu CM: Purple sweet potato color protects mouse liver against d-galactose-induced apoptosis via inhibiting caspase- 3 activation and enhancing PI3K/Akt pathway. Food Chem Toxicol 48: 2500-2507, 2010.

45. Shukla S, Maclennan GT, Hartman DJ, Fu P, Resnick MI and Gupta S: Activation of PI3K-Akt signaling pathway promotes prostate cancer cell invasion. Int J Cancer 121: 1424-1432, 2007.

46. Tokunaga E, Kimura Y, Mashino K, Oki E, Kataoka A, Ohno S, Morita M, Kakeji Y, Baba H and Maehara Y: Activation of PI3K/ Akt signaling and hormone resistance in breast cancer. Breast Cancer 13: 137-144, 2006.

47. Powis G, Ihle N and Kirkpatrick DL: Practicalities of drugging the phosphatidylinositol-3-kinase/Akt cell survival signaling pathway. Clin Cancer Res 12: 2964-2966, 2006.

This work is licensed under a Creative Commons Attribution-NonCommercial-NoDerivatives 4.0 International (CC BY-NC-ND 4.0) License. 